\title{
ESTUDO COMPARATIVO DE ADSORÇÃO DE CORANTE TÊXTIL UTILIZANDO CARVÃO ATIVADO E CONCHAS DE OSTRAS CRASSOSTREA RHIZOPHORAE
}

\author{
T. M. N. PAIVA ${ }^{1}$, P. SILVA ${ }^{1}$, S. ANTERINO ${ }^{1}$, L. C. ZOBY ${ }^{1}$, J. M. FERREIRA ${ }^{1}$, M. A. MOTTA \\ SOBRINHO $^{1}$ \\ ${ }^{1}$ Universidade Federal de Pernambuco, Departamento de Engenharia Química \\ E-mail para contato: tarsilamaira@hotmail.com
}

RESUMO - O incremento no número de lavanderias industriais no agreste pernambucano remete a preocupações como a necessidade da minimização do impacto ambiental causado pelo processo de lavagem do jeans. Essas lavanderias são responsáveis, dentre outros motivos, pela degradação do Rio Capibaribe, principal fonte de água desta região. Neste trabalho, foi aplicada a técnica de planejamento fatorial a fim de avaliar a influência de variáveis dependentes no processo de adsorção do corante aniônico Indosol azul turquesa em carvão ativado convencional pulverizado e conchas das ostras crassostrea rhizophorae calcinadas a $1000{ }^{\circ} \mathrm{C}$ por 3 horas. Os resultados indicaram que a capacidade de adsorção ótima foi obtida quando se utilizou $0,5 \mathrm{~g}$ de adsorvente e $150 \mathrm{rpm}$ para o carvão ativado e $0,5 \mathrm{~g}$ de adsorvente, 100 mesh e $150 \mathrm{rpm}$ para as conchas de ostras. A eficiência do processo foi de aproximadamente $99 \%$ para os dois adsorventes estudados. Os resultados demonstraram que os resíduos de ostras são atrativos na remediação do corante em estudo tanto do ponto de vista de eficiência quanto em relação ao seu baixo custo.

\section{INTRODUÇÃO}

A principal fonte de abastecimento de água do agreste pernambucano é o Rio Capibaribe. A expansão das indústrias têxteis nesta região são uns dos fatores responsáveis pela degradação deste manancial que recebe resíduos químicos provenientes do processo de beneficiamento de peças em jeans (Costa, 2008).

Vários materiais são capazes de tratar eficientemente, por adsorção, efluentes coloridos. Carvões ativados comerciais são os materiais adsorventes mais utilizados no tratamento de água por apresentarem alta eficiência de remoção de corantes em efluentes (Belaid et al., 2013). Porém, o custo relativamente elevado desse material, por vezes, faz com que seu uso seja limitado (El Haddad et al., 2013). Assim, pesquisadores têm estudado materiais alternativos, que são relativamente de baixo custo, e ao mesmo tempo apresentam elevada eficiência de adsorção (Huang et al., 2011; Vucurovic, 2013; Wang e Li, 2013). O uso de tecnologias limpas e adsorventes com preços mais baixos e biodegradáveis pode ser uma boa alternativa para minimizar o impacto ambiental causado pelos efluentes têxteis (El Haddad et al., 2013). O uso de resíduos para tratar efluentes pode aumentar a disponibilidade de materiais como o carvão ativado, para fins mais nobres. 


\section{9 a 22 de outubro de 2014 \\ Florianópolis/SC}

Pesquisas vêm sendo realizadas para o reaproveitamento de resíduo da maricultura na remoção de poluentes em águas. Asaoca et al. (2009) estudaram a remoção de sulfeto de hidrogênio por adsorção em conchas de ostras, obtendo resultados significativos (12 mg S.g ${ }^{-1}$ ). Peña-Rodriguez et al. (2010), avaliaram o potencial das cascas de mexilhão calcinadas para purificar água contaminada com mercúrio. Foi verificada, por esses pesquisadores, uma redução de $90 \%$ na concentração inicial de $\mathrm{Hg}$ (II).

A maricultura representa um dos setores que mais cresce no cenário global de produção de alimentos (Petrielli, 2008). Em Pernambuco, no município de Igarassu, os manguezais sofrem com a poluição ambiental e lixos domésticos, além disso, são encontradas em vários pontos resíduo da maricultura (Borges, 2010), que em grandes quantidades se torna um forte passivo ambiental (ICEPA, 2004).

Com o propósito de encontrar uma solução para um resíduo da maricultura e, ao mesmo tempo, minimizar o efeito poluente das indústrias têxteis do agreste pernambucano sobre seu principal manancial, este trabalho teve como objetivo investigar a capacidade adsortiva de conchas de ostras Crassostrea rhizophorae como adsorvente na remoção de corante de efluentes da indústria têxtil através do processo de adsorção em batelada.

\section{MATERIAIS E MÉTODOS}

\subsection{Materiais}

Foi utilizado o corante aniônico Indosol azul turquesa FBL T 400 (classificado como corante direto), cedido pela Clariant Brasil. O corante apresentou absorvância máxima no comprimento de onda de $608 \mathrm{~nm}$, a medição foi realizada em espectrofotômetro (UV-visível ThermoGenesys 10).

Os adsorventes utilizados nesse estudo foram concha de ostra da espécie Crassostrea rhizophorae, coletadas no litoral norte de Pernambuco (Distrito de Tejucupapo - Goiana/PE) e carvão ativado comercial P.A em pó.

As conchas foram lavadas em água corrente para retirar o excesso de sal e resíduos orgânicos. Posteriormente colocadas em estufa por 3 horas a $60^{\circ} \mathrm{C}$ com o intuito de reduzir sua umidade, em seguida foram trituradas em moinho de rolos e classificadas em peneiras da série de Tyler a 20, 60 e 100 mesh. Estudos prévios indicaram a necessidade de um tratamento para as conchas, por apresentarem baixa eficiência de remoção de corante quando "in natura". Foi realizado tratamento térmico em mufla à temperatura de $1000^{\circ} \mathrm{C}$ por 3 horas (Paiva et al., 2013).

\subsection{Método}

\section{$\underline{\text { Caracterização da superfície dos adsorventes }}$}

A análise da área Superficial Específica pelo método Brunauer-Emmett-Teller (BET) foi 
realizada no equipamento Micromeritics ASAP ${ }^{\circledR} 2420$ Accelerated Surface Area and Porosimetry System do Centro de Tecnologias Estratégicas do Nordeste (CETENE).

A análise por difração de Raios X foi realizada em um difratômetro de marca Rigaku, modelo Ultima, operando com tensão de $40 \mathrm{kV}$ e corrente de $20 \mathrm{~mA}$, utilizando radiação Kalfa do cobre. As distâncias interplanares, em todos os difratogramas, foram expressas em ângtrons $(\AA)$.

\section{Planejamento Fatorial dos Experimentos}

A capacidade adsortiva foi avaliada pela técnica de planejamento fatorial $2^{3}$ para as conchas de ostras e $2^{2}$ para o carvão ativado. Foram investigados alguns dos principais fatores que mais influenciam no processo adsortivo: quantidade (massa) do adsorvente (M), a velocidade de agitação (A) e a granulometria do adsorvente (G). Não foi realizado o planejamento com a variável granulometria para o carvão ativado comercial, pois, este já estava na forma pulverizada.

As condições experimentais estão de acordo com a Tabela 1. Os níveis dos fatores investigados para ambos os corantes estão dispostos na Tabela 2.

Tabela 1 - Condições experimentais para os planejamentos fatoriais $2^{3}$ e $2^{2}$ completo

Corante Indosol azul turquesa FBL T 400

Concentração inicial $15 \mathrm{mg} . \mathrm{L}^{-1}$

Adsorvente

Conchas de ostras e carvão ativado comercial

Granulometria 20,60 e 100 mesh

Volume da solução

$25 \mathrm{~mL}$

Tempo

30 minutos

Temperatura

$30^{\circ} \mathrm{C}$

Tabela 2 - Variáveis e níveis estudados nos planejamentos fatoriais $2^{3}$ e $2^{2}$ completo

\begin{tabular}{|c|c|c|c|}
\hline & \multicolumn{3}{|c|}{ Níveis } \\
\hline Variáveis & -1 & 0 & +1 \\
\hline Massa (g) & 0,5 & 1,25 & 2,0 \\
\hline Granulometria (mesh) & 100 & 60 & 20 \\
\hline Agitação (rpm) & 150 & 300 & 450 \\
\hline
\end{tabular}

Após a adsorção a mistura foi centrifugada a $5000 \mathrm{rpm}$ durante 15 minutos e o sobrenadante foi filtrado em papel de filtro faixa azul (Paiva et al., 2011). Esta ordem de separação do adsorventeadsorbato foi respeitada para não ocorrer a colmatação do filtro, além de acelerar a filtração e a separação adsorvanto/adsorvente (respeitando assim os tempos de contato estabelecidos). As concentrações finais foram determinadas através de um espectrofotômetro UV-Visível Thermo modelo Genesys 10, utilizando cubeta de quartzo de $10 \mathrm{~mm}$. 
Os experimentos foram realizados em duplicata, com triplicata no ponto central, em ordem aleatória e a resposta estudada foi a capacidade adsortiva, ou seja, quantidade de corante adsorvida por unidade de massa do adsorvente (Q).

A capacidade adsortiva é dada pela Equação 1:

$$
Q=\frac{C_{A 0}-C_{A}}{M} x V
$$

na qual $\mathrm{C}_{\mathrm{A} 0}$ é a concentração inicial de adsorvato $\left(\mathrm{mg} \cdot \mathrm{L}^{-1}\right), \mathrm{C}_{\mathrm{A}}$ é a concentração final de adsorvato (mg.L $\left.\mathrm{L}^{-1}\right), \mathrm{V}$ é o volume da solução de corante (L) e M é a quantidade massa de adsorvente (g).

\section{RESULTADOS E DISCUSSÃO}

\section{Caracterização da superfície dos adsorventes}

A área específica dos poros das conchas de ostras Crassostrea rhizophorae foi aumentada em $50 \%$ quando calcinadas em relação às conchas "in natura", já o volume poroso aumentou em $74 \%$. 0 diâmetro do poro permaneceu praticamente inalterado ante e após o tratamento térmico. 0 carvão ativado em pó possui valores superiores a todos os parâmetros analisados nesta caracterização (Tabela 3).

Tabela 3. Resultado das análises da área específica, volume e diâmetro médio dos poros dos adsorventes estudados.

\begin{tabular}{|c|c|c|c|}
\hline & $\begin{array}{c}\text { Conchas de ostras } \\
\text { "in natura" }\end{array}$ & $\begin{array}{c}\text { Conchas de } \\
\text { ostras calcinadas }\end{array}$ & $\begin{array}{c}\text { Carvão ativado } \\
\text { em pó }\end{array}$ \\
\hline $\begin{array}{c}\text { Área superficial }(\mathrm{BET}) \\
\left(\mathrm{m}^{2} \cdot \mathrm{g}^{-1}\right)\end{array}$ & 1,3886 & 2,0865 & 704,2192 \\
\hline $\begin{array}{c}\text { Volume dos } \\
\text { poros }\left(\mathrm{cm}^{2} \cdot \mathrm{g}^{-1}\right)\end{array}$ & 0,003982 & 0,006952 & 300,669 \\
\hline $\begin{array}{c}\text { Diâmetro médio dos } \\
\text { poros }(\AA)\end{array}$ & 327,004 & 317,118 & 0,404546 \\
\hline
\end{tabular}

Pela análise de difração de raios-X (DRX) das conchas de ostras Crassostrea rhizophorae foi possível observar que este adsorvente é formado tipicamente por calcita e após a calcinação o material se apresentou como óxido de cálcio. As conchas apresentaram alta concentração de cálcio e presença de carbono e oxigênio. 
Através desta análise de caracterização, o carvão ativado em pó, apresentou uma banda amorfa, característico de um material não mineral, sendo este por sua vez de origem vegetal.

Planejamento Fatorial utilizando conchas de ostras como adsorvente - Avaliação das melhores condições de quantidade de adsorvente, granulometria e agitação

A Tabela 4 apresenta a matriz de planejamento com a média dos resultados obtidos da variável resposta $(\mathrm{Q})$ em cada combinação de níveis para as variáveis de entrada.

Tabela 4 - Matriz de planejamento para um planejamento fatorial $2^{3}$ utilizando conchas de ostras como adsorvente do corante Indosol azul turquesa

\begin{tabular}{|c|c|c|c|c|}
\hline Ensaios & Agitação $(\mathrm{g})$ & Granulometria (mesh) & Massa (rpm) & $Q\left(\mathrm{mg}^{-1} \mathrm{~g}^{-1}\right)$ \\
\hline 1 & + & + & + & 0,186 \\
\hline 2 & + & + & - & 0,769 \\
\hline 3 & + & - & + & 0,194 \\
\hline 4 & + & - & - & 0,776 \\
\hline 5 & - & + & + & 0,194 \\
\hline 6 & - & + & - & 0,759 \\
\hline 7 & - & - & + & 0,194 \\
\hline 8 & - & - & - & 0,759 \\
\hline 9 & 0 & 0 & 0 & 0,194 \\
\hline 10 & 0 & 0 & 0 & 0,776 \\
\hline 11 & 0 & 0 & 0 & 0,289 \\
\hline
\end{tabular}

+) 2,0 g, 20 mesh, $450 \mathrm{rpm}$; -) 0,5 g, 100 mesh, $150 \mathrm{rpm}$; 0) 1,25 g, 60 mesh, $300 \mathrm{rpm}$

A Tabela 5 mostra os parâmetros da análise de variância (ANOVA) para o ajuste do modelo linear na adsorção do corante Indosol pelas conchas de ostras para as condições experimentais estudadas. Pelos valores observados nesta tabela verificou-se que, o sistema em estudo apresentou $100 \%$ de variância explicável, ou seja, quantidade de resíduos mínima, mostrando assim, um bom ajuste ao modelo matemático aplicado (Barros Neto et al., 2007).

Tabela 5 - Análise da variância para o ajuste do modelo linear

\begin{tabular}{|c|c|c|c|c|c|}
\hline $\begin{array}{c}\text { Fonte de } \\
\text { Variação }\end{array}$ & $\begin{array}{c}\text { Soma } \\
\text { Quadrática }\end{array}$ & $\begin{array}{c}\text { Graus de } \\
\text { Liberdade }\end{array}$ & $\begin{array}{c}\text { Média } \\
\text { Quadrática }\end{array}$ & $\begin{array}{c}\text { Variação } \\
\text { explicada (\%) }\end{array}$ & $\begin{array}{c}\text { Máximo de variação } \\
\text { explicável(\%) }\end{array}$ \\
\hline Regressão & 1,3362 & 6 & 0,2227 & 95,32 & 100 \\
\hline Resíduos & 0,0656 & 9 & 0,0073 & & \\
\hline Falta de Ajuste & 0,0656 & 2 & 0,0328 & & \\
\hline Erro Puro & 0,000005 & 9 & 0,0000 & & \\
\hline Total & 1,4017 & 17 & & & \\
\hline
\end{tabular}

Os coeficientes de regressão da Tabela 5 compõem a Equação 2 que representa os dados 
experimentais ajustados a um modelo empírico quadrático para o Indosol.

$\mathrm{Q}=0,000312 \mathrm{~A}-0,004063 \mathrm{G}-0,288938 \mathrm{M}+0,000313 \mathrm{AG}-0,002312 \mathrm{AM}+0,002063 \mathrm{GM}+0,46$

Observa-se pela Equação 3 que o segundo e terceiro termos, granulometria e quantidade de massa, respectivamente, representaram influência negativa sobre a quantidade adsorvida, ou seja, à medida que se diminui a quantidade de massa e granulometria obtém-se um elevado valor de $\mathrm{Q}$. Como a agitação apresentou influência mínima foi considerado, para economia de energia e redução de custos, trabalhar com a menor velocidade nos experimentos posteriores.

A Figura 1, gráfico de Pareto, comprova que as variáveis que apresentam influência significativa no processo adsortivo do corante Indosol nas cascas de ostra foram a quantidade de adsorvente $(\mathrm{M})$, a granulometria $(\mathrm{G})$, a agitação $(\mathrm{A})$ e a interação entre estas duas últimas. Todavia e efeito da massa no processo adsortivo foi muito superior aos demais.

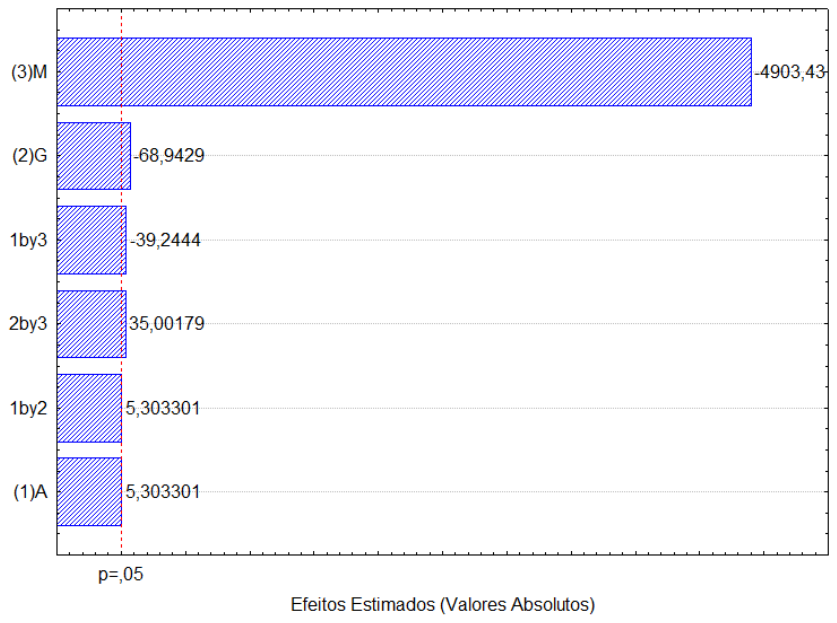

Figura 1 - Diagrama de Pareto dos efeitos estimados. (3) quantidade de massa, (2) granulometria, (1) agitação

A superfície de resposta da capacidade de adsorção está representada na Figura 3. A capacidade de adsorção apresentou uma região de máximo que prevê, segundo o modelo da Equação 3, as condições de maior capacidade de adsorção sobre o corante Indosol. Este valor calculado corresponde a $0,759 \mathrm{mg} \cdot \mathrm{g}^{-1}$. 


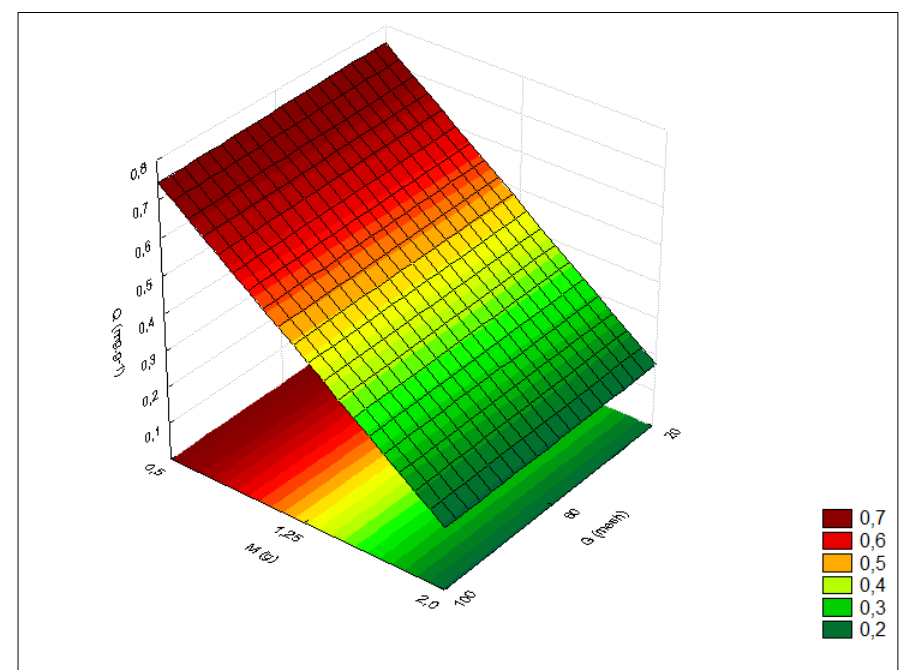

Figura 2 - Superfície de resposta para a quantidade adsorvida Q (mg.g $\left.{ }^{-1}\right)$ do corante Indosol azul turquesa. Efeito da quantidade de massa e da granulometria.

Planejamento Fatorial utilizando carvão ativado como adsorvente - Avaliação das melhores condições de quantidade de adsorvente e agitação

Para o carvão ativado, os dados das concentrações finais se mostraram muito parecidos nas repetições, assim não foi possível realizar nenhum teste estatístico e, dessa forma, não foi possível estimar a significância estatística dos efeitos e dos parâmetros de regressão.

A Tabela 6 apresenta a matriz de planejamento com a média dos resultados obtidos da variável resposta $(\mathrm{Q})$ em cada combinação de níveis para as variáveis de entrada, referente aos ensaios, utilizando o carvão ativado comercial em pó como adsorvente na remoção do corante Indosol azul turquesa.

Tabela 6 - Matriz de planejamento para um planejamento fatorial $2^{2}$ utilizando carvão ativado comercial como adsorvente do corante Indosol azul turquesa

\begin{tabular}{|c|c|c|c|}
\hline Ensaios & Agitação (RPM) & Massa $(\mathrm{g})$ & $q_{t}\left(\mathrm{mg}^{-\mathrm{g}^{-1}}\right)$ \\
\hline 1 & + & + & 0,194 \\
\hline 2 & + & - & 0,771 \\
\hline 3 & - & + & 0,194 \\
\hline 4 & - & - & 0,776 \\
\hline 5 & 0 & 0 & 0,311 \\
\hline
\end{tabular}

+) 2,0 g, $450 \mathrm{rpm}$; -) 0,5 g, $150 \mathrm{rpm}$;0) 1,25 g, $300 \mathrm{rpm}$ 
De acordo com o gráfico de Pareto (Figura 3), a única variável que apresente influência significativa na adsorção do corante Indosol pelo carvão ativado comercial foi a quantidade de massa. Quanto menor a quantidade de massa no processo maior a quantidade de corante adsorvida, isso ocorre pelo fato do carvão possuir muitos sítios ativos desocupados uma vez que a concentração do corante é baixa. A agitação não influenciou no processo. O maior valor para a quantidade adsorvida por massa de adsorvente (Q) foi de $0,776 \mathrm{mg} \cdot \mathrm{g}^{-1}$, utilizando uma massa de $0,5 \mathrm{~g}$ de adsorvente e uma agitação de $150 \mathrm{rpm}$. O coeficiente de correlação múltipla $\left(\mathrm{R}^{2}\right)$ foi igual a 0,93 .

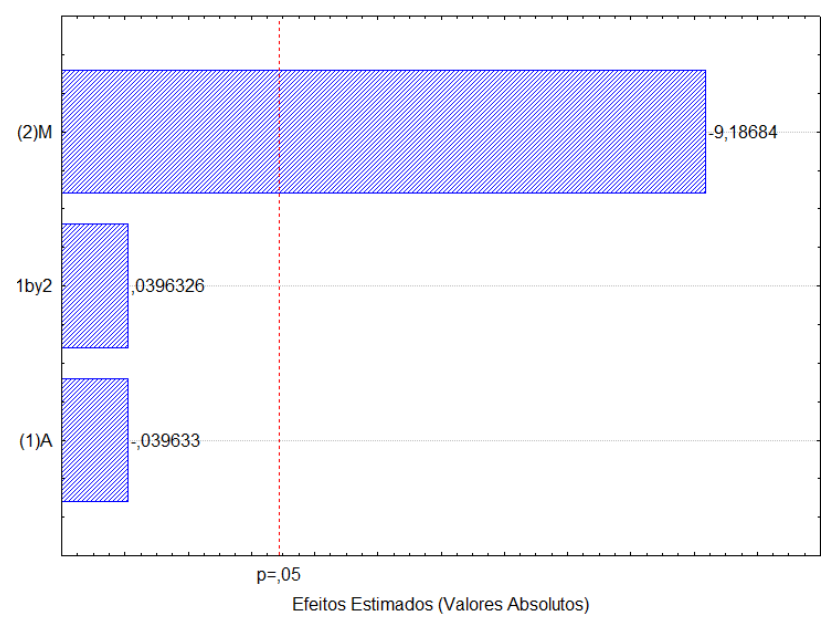

Figura 3 - Diagrama de Pareto dos efeitos estimados. (2) quantidade de massa, (1) agitação

Utilizando a técnica de planejamento fatorial para avaliar as melhores condições de trabalho na adsorção de corantes têxteis, Bandeira, et al. (2014), obtiveram cerca de $98 \%$ de remoção do corante reativo amarelo bifuncional 3R-200\% empregando dolomita termicamente modificada, quando utilizou a menor massa de adsorvente.

Silva Filho et al. (2005) destacaram que os níveis e as variáveis que mais influenciaram na adsorção do Remazol Black B por lama vermelha neutralizada foi menor velocidade de agitação e a menor quantidade de adsorvente, chegando a um percentual de $70 \%$ de remoção.

Maiores capacidades de adsorção obtidas para as menores massas podem ser um indicativo de que para o nível superior deste parâmetro não há saturação do adsorvente.

A remoção de corante do meio aquoso foi acima de $99 \%$ tanto para as cascas de ostra quanto para o carvão ativado como adsorvente.

As condições ótimas de trabalho, quantidade de adsorvente $(0,5 \mathrm{~g})$ e agitação $(150 \mathrm{rpm})$, foram iguais para os dois adsorventes utilizados. 
Nas melhores condições do processo adsortivo, não foram verificadas diferenças significativas entre os maiores valores obtidos para a quantidade adsorvida do corante Indosol azul turquesa pelas conchas da crassostrea rhizophorae $\left(0,759 \mathrm{mg} \cdot \mathrm{g}^{-1}\right)$ e pelo carvão ativado comercial $\left(0,776 \mathrm{mg} \cdot \mathrm{g}^{-1}\right)$.

\section{CONCLUSÃO}

Pelo estudo do planejamento fatorial, a condição ótima para a utilização das cascas de ostras foi quantidade de adsorvente $(\mathrm{M})$ de $0,5 \mathrm{~g}$, granulomertia $(\mathrm{G})$ de 100 mesh e velocidade de agitação (A) de $150 \mathrm{rpm}$. Para o carvão ativado comercial pulverizado a melhor condição no processo foi quantidade de adsorvente $(\mathrm{M})$ de $0,5 \mathrm{~g}$ e velocidade de agitação (A) de $150 \mathrm{rpm}$.

A quantidade máxima adsorvida pelas cascas de ostra foi de $0,759 \mathrm{mg}^{-\mathrm{g}^{-1}}$ com eficiência de $98,4 \%$ aproximadamente e para o carvão foi de $0,776 \mathrm{mg} \cdot \mathrm{g}^{-1}$ com eficiência de remoção de $99,8 \%$.

Os dois adsorventes estudados apresentaram uma boa capacidade de remoção do corante Indosol azul turquesa e para as condições experimentais aplicadas neste trabalho constata-se que o resíduo das cascas de ostras crassostrea rhizophorae pode ser uma atrativa opção para remoção de corantes em efluentes de indústria têxtil, uma vez que se destaca pelo seu baixo custo de aquisição quando comparado com o carvão ativado comercial, além de dar aplicação a um resíduo.

\section{REFERÊNCIAS}

ASAOKA, S.; YAMAMOTO, T.; KONDO, S.; HAYAKAWA, S. Removal of hydrogen sulfide using crushed oyster shell from pore water to remediate organically enriched coastal marine sediments. Bioresource Technology. v. 100, p. 4127-4132, 2009.

BANDEIRA, R. L. C.; SIlVA, A. A.; FREITAS, M. A. G.; SILVA, M. L. P.; GOMES, K. K . P. Estudo pré-eliminar de remoção do corante reativo amarelo bifuncional 3r-200\% por dolomita modificada. Anais do X Encontro Brasileiro sobre adsorção, 2014.

BARROS NETO, B.; SCARMINIO, I. S.; BRUNS, R. E. Como fazer experimentos: pesquisa e desenvolvimento na ciência e na indústria. v.1, 4.ed. Coleção Livros-Textos, Campinas: UNICAMP, 2007. $480 \mathrm{p}$

BELAID, K. D.; KACHA, S.; KAMECHE, M.; DERRICHE, Z. Adsorption kinetics of some textile dyes onto granular activated carbon.Journal of Environmental Chemical Engineering.v. 1, p. 496-503, 2013.

BORGES, S.Latão em Igarassu: Rio São Domingos tem até sofá. Recife, nov. 2010. Disponível em: <http://migre.me/3MpFu>. Acessoem: 02/12/2010. 
COSTA, A. F. S. Aplicação de tratamentos biológicos e físico-químico em efluentes de lavanderia e tinturaria industriais do município de Toritama no estado de Pernambuco. Dissertação de Mestrado. Universidade Católica de Pernambuco. Recife-PE, 2008.

EL HADDAD, M.; SLIMANI, R.; MAMOUNI, R.; ELANTRI, S.; LAZAR, S. Removal of two textile dyes from aqueous solutionsonto calcinedbones. Journal of the Association of Arab niversities for Basic and Applied Sciences. v. 14, p.51-59, 2013.

HUANG, X.; BIN, J.; BU, H.; JIANG, G.; ZENG, M. Removal of anionic dye eosin Y from aqueous solution using ethylenediamine modified chitosan. Carbohydrate Polymers. v. 84, p. 1350-1356, 2011.

ICEPA - Comissão Estadual de Planejamento Agrícola-SC. Síntese Anual da Agricultura Catarinense. Florianópolis-SC, 321 p., 2004.

PEÑA-RODRÍGUEZ，S.; FERNÁNDEZ-CALVIÑO， D.; NÓVOA-MUÑOZA，J. C.; ARIASESTÉVEZA, M.; NÚÑEZ-DELGADO, A.; FERNÁNDEZ-SANJURJO, M. J.; ÁLVAREZRODRÍGUEZ, E. Kinetics of Hg (II) adsorption and desorption in calcined mussel shells. Journal of Hazardous Materials. v. 180, p. 622-627, 2010.

PETRIELLI, F. A. S. Viabilidade técnica e econômica da utilização comercial das conchas de ostras descartadas na localidade do Ribeirão da Ilha. Dissertação de Mestrado. Universidade Federal de Santa Catarina, Florianópolis-SC, 2008.

SILVA FILHO, E. B.; JUNIOR, W. B.; SILVA, V. L.; ALVES, M. C. M.; MOTTA, M. Tratamento de efluentes têxteispor adsorção em lama vermelha. Anais do $23^{\circ}$ Congresso Brasileiro de Engenharia Sanitária e Ambiental, 2005.

VUCUROVIC, V. M.; RAZMOVSKY, R. N.; MILJIC, U. D.; PUSCAS, V. S. Removal of cationic and anionic azo dyes from aqueous solutions by adsorption on maize stem tissue. Journal of the Taiwan Institute of Chemical Engineers. 2014.

WANG, L.; Li, J. Adsorption of C.I. Reactive Red 228 dye from aqueous solution by modified cellulose from flax shive: Kinetics, equilibrium, and thermodynamics. Industrial Crops and Products. v. 42, p. 153-158, 2013. 